\title{
Ser mulher, gestar e parir: sentidos em transição e desafios para o setor saúde
}

A incorporação de mulheres ao mercado formal de trabalho e a contracepção, agendas intensificadas na segunda metade do século XX, permitiram que as mulheres pudessem ter projetos próprios. Redução da dependência do casamento ou da família de origem, decisão sobre o número desejado de filhos e o melhor momento para tê-los mudaram opções sobre maternidade, gravidez e parto ${ }^{1}$. Entretanto, estas mudanças não ocorreram de forma linear para todas as mulheres. Hierarquias sociais produzidas na intercessão entre classe social e raça/etnia determinam acessos distintos aos benefícios conquistados nesta transição, em detrimento das mais pobres. Mesmo os avanços obtidos nesta área nos últimos anos - decorrentes em parte de políticas de redução da pobreza e da desigualdade social, não foram suficientes para garantir a qualidade da atenção à saúde das mulheres durante a gestação e o parto².

Curiosamente, as desigualdades entre as mulheres não impediram que um novo discurso em relação à maternidade fosse se tornando hegemônico. Não mais a ideia de uma contingência biológica ou um suposto instinto. Tornar-se mãe passa a ser uma escolha, requisito para autorrealização. Nesta perspectiva as práticas relativas à parturição e ao aleitamento tornam-se também parte de um projeto de construção de si como mulher-mãe, exigindo apoio e reconhecimento do seu papel de agentes do seu processo reprodutivo. Os artigos apresentados nesta edição, de diferentes formas tratam das repercussões para as práticas de saúde das mudanças de sentidos atribuídos à maternidade. Assim, na definição das competências necessárias para a atuação sobre os direitos sexuais e reprodutivos na atenção básica, a ética ganha destaque, assinalando a inflexão necessária para atender à nova compreensão do ato de gestar e parir.

Sob outra perspectiva, os textos sobre os modelos de parto mostram a participação do setor saúde no processo de mudanças da relação das mulheres com o ato de parir. Alguns artigos apontam desafios para a oferta de atenção de qualidade. Por exemplo, os autores assinalam a presença de preconceitos por parte dos profissionais contra mulheres não brancas, inclusive na Rede Cegonha. Tais discriminações refletem como as ideologias de gênero e o racismo atravessam o trabalho em saúde. E um grupo de artigos apresenta lacunas na garantia da segurança reprodutiva. Alguns autores analisam outros aspectos da saúde das mulheres: problemas relativos ao climatério e à menopausa, à obesidade, à situação de encarceramento e às trajetórias de exclusão.

Como sugerem diferentes autores, as práticas de saúde relacionadas à produção de seres humanos a partir do corpo das mulheres ainda não reconhecem a maternidade como um trabalho social feminino em prol da sociedade, o que urge ser feito, ao lado do reconhecimento das mulheres como agentes das próprias vidas.

Wilza Vieira Villela ${ }^{1}$

${ }^{1}$ Departamento de Medicina Preventiva, Universidade Federal de São Paulo. São Paulo SP Brasil.

\section{Referências}

1. Moynihan L. Lindsay Moynihan MAE Thesis" Contemporary Motherhood; An Intimate Look at Mothers in the 21st Century" 2013 [dissertation]. Departamento de Medicina Preventiva

2. Leal MC, Szwarcwald CL, Almeida PVB, Aquino EML, Barreto ML, Barros F, Victora C. Saúde reprodutiva, materna, neonatal e infantil nos 30 anos do Sistema Único de Saúde (SUS). Cien Saude Colet 2018; 23(6):1915-1928. 